\title{
LEVIN-RICHARDSON, SARAH. THE BROTHEL OF POMPEII: SEX, CLASS, AND GENDER AT THE MARGINS OF ROMAN SOCIETY. CAMBRIDGE, UK, E NOVA YORK, NY: CAMBRIDGE UNIVERSITY PRESS, 2019. 243 P. ISBN: 978-1-108-49687-2.
}

Fabrício Sparvoli ${ }^{1}$

Sarah Levin-Richardson, professora assistente de Estudos Clássicos na Universidade de Washington, Seatle, traz à luz em seu mais recente livro, intitulado The brothel of Pompeii: sex, class, and gender at the margins of Roman Society (2019), uma pesquisa minuciosa e detalhada sobre múltiplos aspectos acerca do famoso bordel de Pompeia (VII.12.18-20). Recebendo cerca de 455 visitantes por hora em um dia comum de visitação turística, esse bordel vem inspirando um igualmente expressivo interesse acadêmico, sobretudo devido aos grafites aí encontrados. É essa produção acadêmica que Levin-Richardson se propõe revisitar, expandir e reavaliar, abordando, para além das inscrições, a espacialidade do bordel, os achados materiais desenterrados nele e suas representações visuais (afrescos). Esta investigação, que poderia ser corretamente qualificada como abrangente, recupera a experiência de clientes em busca de sexo (mas não apenas), de prostitutas que subvertem sua exploração no sentido de constituir uma agência em prol de si, de prostitutos buscando retardar seu envelhecimento degradante.

O livro contém uma Introdução, à qual seguem duas partes. A primeira (capítulos primeiro a quinto), trata o bordel de uma perspectiva arqueológica, abordando os aspectos físicos do edifício e descrevendo sua espacialidade, sua escavação, reconstrução e conservação. A segunda (capítulos sexto a oitavo), assume uma abordagem mais próxima à história social daqueles que trabalharam ou passaram pelo bordel. Compõem o livro, ainda, dois apêndices: o A, que reproduz alguns trechos do diário de escavação, de 1862; e o B, que lista os grafites mencionados, oferecendo sua localização e uma proposta de tradução.

O estudo inicia-se com uma introdução geral, onde a autora descreve o espaço que será seu objeto de análise, bem como as balizas teóricometodológicas que orientarão sua pesquisa. Seu objeto constitui-se naquele

1 Mestrando, FAPESP - Universidade de São Paulo, São Paulo, Brasil. E-mail: fabricio.godoy@usp.br

Heródoto, Unifesp, Guarulhos, v.5, n.1 - 2020.1. p. 101-106

DOI: $10.34024 /$ herodoto.2020.v5.11787 
que, segundo a autora, é o único edifício pompeiano que pode ser corretamente caracterizado como intencionalmente construído para abrigar trabalho sexual. Soterrada em 79 d.C. e escavada em 1862, a estrutura sofreu intervenções de restauro e reconstrução entre os anos 1907 e 1909 (quando se resconstroi o piso superior), em 1950 (após destruição parcial causada por um bombardeio dos aliados, na Segunda Guerra Mundial) e entre 2004 e 2006. Afora alguns elementos debatíveis, como a largura do balcão superior e a localização de janelas neste mesmo balcão, a estrutura conserva, segundo a autora, grande fidelidade em relação ao que teria sido a sua configuração original.

Do ponto de vista teórico-metodológico, a autora define o que seja um bordel seguindo, conforme ela declara, os trabalhos de Andrew WallaceHadrill e de Thomas McGinn. De acordo com o primeiro autor, para que uma edificação seja classificada como um bordel era preciso que ela possuísse: camas de alvenaria em quartos de pequena dimensão; afrescos explicitamente sexuais; e um conjunto de grafites explicitamente eróticos. Já de acordo com o segundo autor, um bordel caracterizava-se, para além disso, por ser uma edificação cuja fonte econômica primária fosse o trabalho sexual e que hospedasse múltiplos trabalhadores/as, simultaneamente. Assim caracterizado, o único bordel pompeiano, LevinRichardson conclui, seria aquele que situado em VII.12.18-20.

Bordeis, então, como argumenta a autora, seriam espaços particularmente excepcionais, incomuns, dado que seus clientes poderiam procurar por serviços sexuais em outros lugares. Assim, a questão que ela coloca é, exatamente, a de por que - sendo o bordel um lugar excepcional e, sobretudo, existindo a possibilidade de se encontrar prazeres sexuais em outros lugares e outras ocasiões - clientes procuravam, então, aquele lugar. A hipótese que ela explorará, ao longo do livro, é a de que os clientes procuravam o bordel para ter uma experiência ficcional e temporária de classe e de masculinidade normativa. Ao utilizarem o bordel, homens de diferentes níveis sociais poderiam experienciar por um momento (e por um preço) práticas que imitassem a vida de homens de status superior e, assim, reafirmar temporariamente sua masculinidade. Ou seja, o bordel vendia não apenas sexo, mas também lazer e masculinidade normativa. Para provar sua hipótese ao longo dos capítulos, a autora defende abordar o bordel em seus próprios termos, em sua totalidade, e não como se costuma fazer, lendo-o exclusivamente a partir da perspectiva dos textos literários (muito embora Levin-Richardson também se utilize deles).

O capítulo primeiro, assim, trata da arquitetura do bordel. Após descrevêla, a autora aponta as similaridades dessa estrutura com outras do mesmo

Heródoto, Unifesp, Guarulhos, v.5, n.1 - 2020.1. p. 101-106

DOI: $10.34024 /$ herodoto.2020.v5.11787 
contexto histórico, como os espaços utilitários da Casa de Menandro (I.10.4). Semelhanças de espaços e de mobília entre o bordel e outras casas aristocráticas seriam indício de que o bordel proporcionava uma experiência menos simplória e hostil do que aquela que um turista, atualmente, talvez imagine ao visitá-lo. Ao contrário, dadas estas semelhanças, visitar o bordel em seu contexto original, segundo LevinRichardson, seria uma maneira possível de acessar alguns aspectos, inacessíveis em outras circunstâncias, pertencentes ao mundo da alta sociedade pompeiana, como a casa de Menandro. De modo semelhante, clientes que ingressassem pela porta 18 seriam expostos a oito afrescos, perante os quais eles poderiam parar e observar detidamente, como se estivessem em uma residência aristocrática ricamente adornada. Em suma, a própria estrutura física do bordel, parcialmente semelhante à de casas aristocráticas, teria sido intensionalmente construída de modo a propiciar uma experiência de fantasia de status elevado, possibilitando que clientes vindos dos mais diversos níveis sociais construíssem, mesmo que momentaneamente, uma ficção de masculinidade normativa e aristocrática.

O capítulo segundo trata dos achados materiais desenterrados durante a escavação de 1862. Esses achados receberam pouca atenção nos estudos sobre o bordel, de acordo com Levin-Richardson. Todos esses diferentes objetos seriam indícios de diferentes serviços ofertados no bordel, como cuidado corporal e alimentação, os quais, na interpretação de LevinRichardson, confirmam o fato de que o bordel era um espaço aonde se ia atrás de um conjunto de experiências que fossem mais do que sexual. Ao dividir uma refeição com uma prostituta local, homens comuns poderiam experimentar situações próximas àquelas que homens da elite tinham em seus banquetes: dividir bebidas e confidências, conversar com cortesãs.

O capítulo terceiro aborda a materialidade dos grafites encontrados nas paredes do bordel, reconstituindo sua distribuição física e a experiência multissensorial implicada na sua escrita. Muito embora o número total de grafites do bordel varie na contagem da autora ao longo do livro (no mapa da página 50, contam-se 134, enquanto no Apêndice B, 142), a análise deles é possivelmente a contribuição mais importante dada por esta pesquisa. Levin-Richardson não apenas os interpreta em seus contextos espaciais de origem com precisão, como também situa cada grafite em sua cacofonia original de mensagens múltiplas e sobrepostas. Cada grafite é interpretado, assim, em sua relação espacial e discursiva com os demais. $\mathrm{O}$ próprio ato de escolher o conteúdo e a localização dos grafites, como aponta Levin-Richardson, era uma experiência multissensorial e poderia 
envolver subir em camas de alvenaria, por exemplo. As paredes do bordel, então, funcionavam como um quadro de mensagens comunitário, onde aqueles que escreviam podiam criar suas próprias personas, deixar recados, ou enviar mensagens para amigos.

O quarto capítulo analisa os oito afrescos que se encontram no hall de entrada do bordel, numerados de I a VIII. Como chama atenção LevinRichardson, os afrescos são compostos por cenas que não contrariam as práticas que os romanos tinham como aceitáveis, do ponto de vista sexual. Assim, não há cenas de fellatio, de irrumatio, ou atos congêneres (ao contrário do que pode ser encontrado, por exemplo, nos afrescos das Termas Suburbanas, objeto de intensa discussão historiográfica). Essa escolha por representações que condizem com a moralidade sexual romana amplamente aceita ajudaria a construir a fantasia que o cliente procurava, uma vez que não o exporia a representações sexuais vexatórias ou indesejadas. Também os afrescos, então, operavam na construção da experiência masculina que o bordel proporcionava.

O capítulo quinto examina o andar superior do edifício. Levin-Richardson começa por resgatar as diferentes interpretações que foram dadas anteriormente para o uso desse andar, geralmente negligenciado pela historiografia: alojamento das prostitutas que trabalhavam no térreo; moradia do cafetão; prostíbulo para os mais ricos; entre outras. Contudo, atentando-se para a disposição dos espaços, Levin-Richardson conclui que o piso superior era um espaço independente do bordel, possuindo funções outras. Funções, aliás, que poderiam ser variadas, incluindo desde a hospedagem temporária de visitantes à locação permanente de famílias.

O capítulo sexto explora a clientela do bordel. Como demonstra LevinRichardson, determinar o status social ou a etnicidade dos clientes não é tão simples quanto se poderia pensar. De qualquer modo, ela conclui que, dado os baixos preços dos serviços ali oferecidos, o bordel poderia ser frequentado por clientes de um largo espectro social, de escravos a nascidos livres, de pompeianos a forasteiros. Com efeito, era esse baixo preço que permitiria a homens de origem subalterna fantasiarem uma experiência de classes abastadas, conforme mencionado anteriormente.

O sétimo capítulo retrata a experiência das prostitutas. Como indicam alguns grafites analisados, é possível que ao menos uma parcela das mulheres que se prostituíam no bordel fosse ou de origem livre ou libertas. A exploração dessas prostitutas, como demonstra a autora de modo interessante, dava-se não apenas pelo trabalho sexual, mas também através de trabalho emocional. Assim, as prostitutas não apenas cediam seus

Heródoto, Unifesp, Guarulhos, v.5, n.1 - 2020.1. p. 101-106

DOI: 10.34024/herodoto.2020.v5.11787 
corpos em troca de dinheiro, mas elas participavam, igualmente, no processo de construção da experiência de ócio, lazer e masculinidade de seus clientes. Ao envolverem-se nesse tipo de serviço emocional, por sua vez, as prostitutas tinham uma possibilidade privilegiada de construir agência própria, transformando seus clientes em objetos de suas ações. Assim, um cliente que procurasse estabelecer um relacionamento afetivo com uma prostituta poderia ser usado, por ela, como fornecedor de pequenos presentes, como perfumes (cujos frascos são atestados entre os achados arqueológicos do bordel). Por outro lado, através de grafites prostitutas poderiam não apenas deixar inscrições que agradassem seus clientes, incentivando-os a retornarem, como também poderiam criar personas próprias e complexas. Como demonstra a autora, a prostituição feminina, então, poderia permitir a criação de identidades próprias e de agência feminina, ressignificando a exploração em autopromoção.

O oitavo e último capítulo trata da vida dos prostitutos. A vida desses homens assemelhava-se, em muitos aspectos, à das prostitutas. Eles também tinham que fornecer trabalho emocional, para além de trabalho sexual, e possuíam, igualmente, pequenas oportunidades de agência, transformando exploração em autopromoção. Duas diferenças, porém, existiam entre prostitutos e prostitutas: em primeiro lugar, o envelhecimento entre os homens era mais problemático que entre as mulheres, o que fazia com que eles tivessem que buscar meios de retardar o aparecimento de pelos corporais, por exemplo; em segundo lugar, os prostitutos, sendo capazes de penetrar seus clientes, possuíam um meio adicional de coerção e defesa contra clientes mal comportados.

Encerra o livro uma conclusão e dois apêndices, o A e o B. Na conclusão, a autora busca sumarizar os principais pontos por ela tratados: a relação do bordel com outros espaços do contexto pompeiano; a sobreposição de categorias sociais, tratadas pela historiografia contemporânea com maior rigidez do que apontado pelas evidências antigas, como a da prostituta e a da cortesã; e a transformação de contextos de exploração sexual e emocional em possibilidade de agência. $\mathrm{O}$ Apêndice $\mathrm{A}$ transcreve alguns trechos do diário da escavação de 1862, enquanto o Apêndice B é uma lista dos grafites encontrados no bordel (muito embora a contagem, como dissemos acima, varie ao longo do livro).

Ao fornecer uma exposição sucinta do livro The brothel of Pompeii: sex, class, and gender at the margins of Roman Society, de Sarah Levin-Richardson (2019), procuramos demonstrar, capítulo por capítulo, os elementos principais na pesquisa da autora. Ao combinar diferentes abordagens arqueológica, arquitetônica, epigráfica, literária, social -, a autora fornece

Heródoto, Unifesp, Guarulhos, v.5, n.1 - 2020.1. p. 101-106

DOI: $10.34024 /$ herodoto.2020.v5.11787 
uma interpretação que pode justamente ser qualificada como abrangente, oferecendo uma releitura abrangente e inovadora não apenas de um dos lugares mais visitados do sítio arqueológico de Pompeia, mas também da experiência daqueles clientes, prostitutos e prostitutas que ali estavam - às margens da sociedade romana.

\section{Referências bibliográficas}

LEVIN-RICHARDSON, Sarah. The brothel of Pompeii: sex, class, and gender at the margins of roman society. Cambridge, UK, and New York, NY: Cambridge University Press, 2019. 243 p. 